\title{
Overcoming resistance and barriers to the use of local estrogen therapy for the treatment of vaginal atrophy
}

This article was published in the following Dove Press journal:

International Journal of Women's Health

II October 2012

Number of times this article has been viewed

\section{Lisa A Chism}

Karmanos Cancer Institute, Alexander JWalt Comprehensive Breast Center, Detroit, Michigan, USA
Correspondence: Lisa A Chism Alexander JWalt Comprehensive Breast Center, Karmanos Cancer Institute, 4I 00 John R, Detroit, MI 4820I, USA

Tel +l 3 I3 5769326

Fax +I 3135768379

Email lisachism@comcast.net
Abstract: The purpose of this review is to summarize current information regarding the pathophysiology and management of vaginal atrophy (sometimes called "atrophic vaginitis") and to identify barriers to its treatment with local (or "topical") vaginal estrogen therapy. Relevant clinical trials, meta-analyses, and reviews were identified through the PubMed database. Local estrogen therapy is effective and safe for treatment of vaginal atrophy; however, barriers to treatment (eg, patient reluctance to discuss the condition, misinformation, incomplete understanding of the effectiveness and safety of available therapies) result in its underuse. Health care providers can help overcome barriers to effective treatment of vaginal atrophy by facilitating discussion with women about vaginal health. Discussions should occur at routine preventive health care examinations and during episodic visits when patients present with symptoms of vaginal atrophy. Education and counseling should include information on the importance of maintaining vaginal health and the benefits and risks of treatment, including the demonstrated effectiveness and safety profile of low-dose local estrogen therapy.

Keywords: atrophic vaginitis, vaginal health, hormone therapy, local estrogen

\section{Introduction}

Vaginal atrophy is a common condition, with related symptoms affecting up to about half (45\%) of postmenopausal women ${ }^{1,2}$ and almost two-thirds (61.5\%) of postmenopausal breast cancer survivors. ${ }^{3}$ It is characterized by vaginal dryness, dyspareunia, vaginal itching, discharge, and pain. ${ }^{4}$ Urinary symptoms, including frequent urinary tract infection and incontinence, are also commonly present (Table 1).

For many women, vaginal atrophy interferes with normal sexual functioning. ${ }^{5-7}$ Vaginal atrophy may cause discomfort or pain during intercourse, difficulty in achieving orgasm, decreased sexual desire, embarrassing vaginal and urinary symptoms, and diminished perception of sexual attractiveness. These symptoms may reduce intercourse frequency, interfere with personal relationships, and decrease feelings of intimacy. $^{6}$

Despite the prevalence of vaginal atrophy among postmenopausal women, the topic of vaginal health is frequently absent in preventive health evaluations. Furthermore, many effective treatments for vaginal atrophy are available. Therefore, it is prudent to review the pathophysiology, current treatment recommendations, safety profile of low-dose local vaginal estrogen, and strategies to overcome barriers to the effective treatment of vaginal atrophy. 
Table I Symptoms and signs of estrogen deficiency and vaginal atrophy $4,8,10$

\begin{tabular}{|c|c|c|}
\hline System & Symptoms & Physical and functional changes \\
\hline \multirow[t]{16}{*}{ Genital } & Dryness & Thin, pale, and dry vulvar and vaginal tissue \\
\hline & Dyspareunia & Inflammation of vaginal walls \\
\hline & Itching & Vaginal petechiae, purpura, or ecchymoses \\
\hline & Discharge & Loss of rugal folds; obliteration of fornices \\
\hline & Pain & Shortened, narrowed vagina \\
\hline & & Loss of vaginal elasticity \\
\hline & & Diminished vaginal blood flow \\
\hline & & Reduced sebaceous secretions \\
\hline & & Loss of labial fat pad \\
\hline & & Pendulous labia majora; less distinct labia minora \\
\hline & & Shortening of prepuce and excessive exposure of clitoris \\
\hline & & Pubic hair loss \\
\hline & & $\begin{array}{l}\text { Abnormal vaginal maturation index ( } \downarrow \text { superficial layer cells; } \\
\uparrow \text { Parabasal and intermediate cells) }\end{array}$ \\
\hline & & Increase of vaginal $\mathrm{pH}$ above 5.0 \\
\hline & & Increased susceptibility to trauma, infection, and pain \\
\hline & & Minor lacerations (peri-introital/posterior fourchette) \\
\hline \multirow[t]{10}{*}{ Urinary } & Frequency & Mucosal thinning (urethra, bladder) \\
\hline & Urgency & Urethral shortening \\
\hline & Burning with urination & $\downarrow$ Periurethral collagen \\
\hline & Incontinence & Urethral caruncle \\
\hline & Recurrent urinary tract infection & Urethral prolapse \\
\hline & & Cystocele \\
\hline & & Sphincter weakening \\
\hline & & $\downarrow$ Bladder storage capacity \\
\hline & & $\uparrow$ Post-void residual urine volume \\
\hline & & $\uparrow$ Uninhibited detrusor muscle contractions \\
\hline
\end{tabular}

Notes: $\downarrow$, decreased; $\uparrow$, increased.

\section{Causes of vaginal atrophy}

Estrogen maintains vaginal health through interaction with estrogen receptors in the vagina. ${ }^{8}$ The North American Menopause Society (NAMS) notes that vaginal atrophy is most commonly associated with the diminished estrogen levels associated with menopause and aging. ${ }^{9}$ Low levels of estrogen in the postmenopausal state lead to gradual changes in the urogenital system, including reduced collagen content and thinning of epithelium, altered appearance and function of smooth muscle cells, increased density of connective tissue, fewer blood vessels, decreased enervation and hyperplasia of terminal nociceptor nerve fibers. ${ }^{8,10}$ These changes can result in reduced flexibility of the vaginal vault, reduced vaginal blood flow, altered sensation, and increased $\mathrm{pH}$.

Additionally, cancer treatments (surgery, pelvic radiation, chemotherapy, and endocrine therapy) and chemoprevention therapies may cause or contribute to vaginal atrophy by modifying endocrine activity (which particularly affects the vaginal epithelium), impairing vascular supply to the vaginal tissue or altering the anatomy of vaginal canal. ${ }^{9}$ Symptoms of vaginal atrophy are commonly associated with endocrine breast cancer therapies, including tamoxifen (when used in premenopausal women) and aromatase inhibitors. ${ }^{11}$ Symptoms may also arise in premenopausal women who undergo temporary induction of menopause for treatment of hormone-sensitive advanced breast cancer and in women at high risk for breast or ovarian cancer who undergo bilateral oophorectomy. ${ }^{11}$

\section{Treatment}

Nonhormonal therapies (eg, vaginal moisturizers, lubricants, continued sexual activity) are considered first-line therapies for women with vaginal atrophy (Figure 1). ${ }^{9}$ However, while these therapies may provide symptom relief, they do not address the underlying condition (loss of vaginal integrity due to estrogen deficiency). NAMS therefore recommends that nonhormonal therapies should be followed by a discussion of hormonal therapies, according to the patient's preference, with consultation from her oncologist. ${ }^{9}$

Estrogen therapy, delivered systemically or locally (to limit systemic absorption), may be considered for women in whom nonhormonal therapies are ineffective. ${ }^{9}$ If vasomotor symptom relief or osteoporosis prevention is desired and the patient has no contraindications or objections 


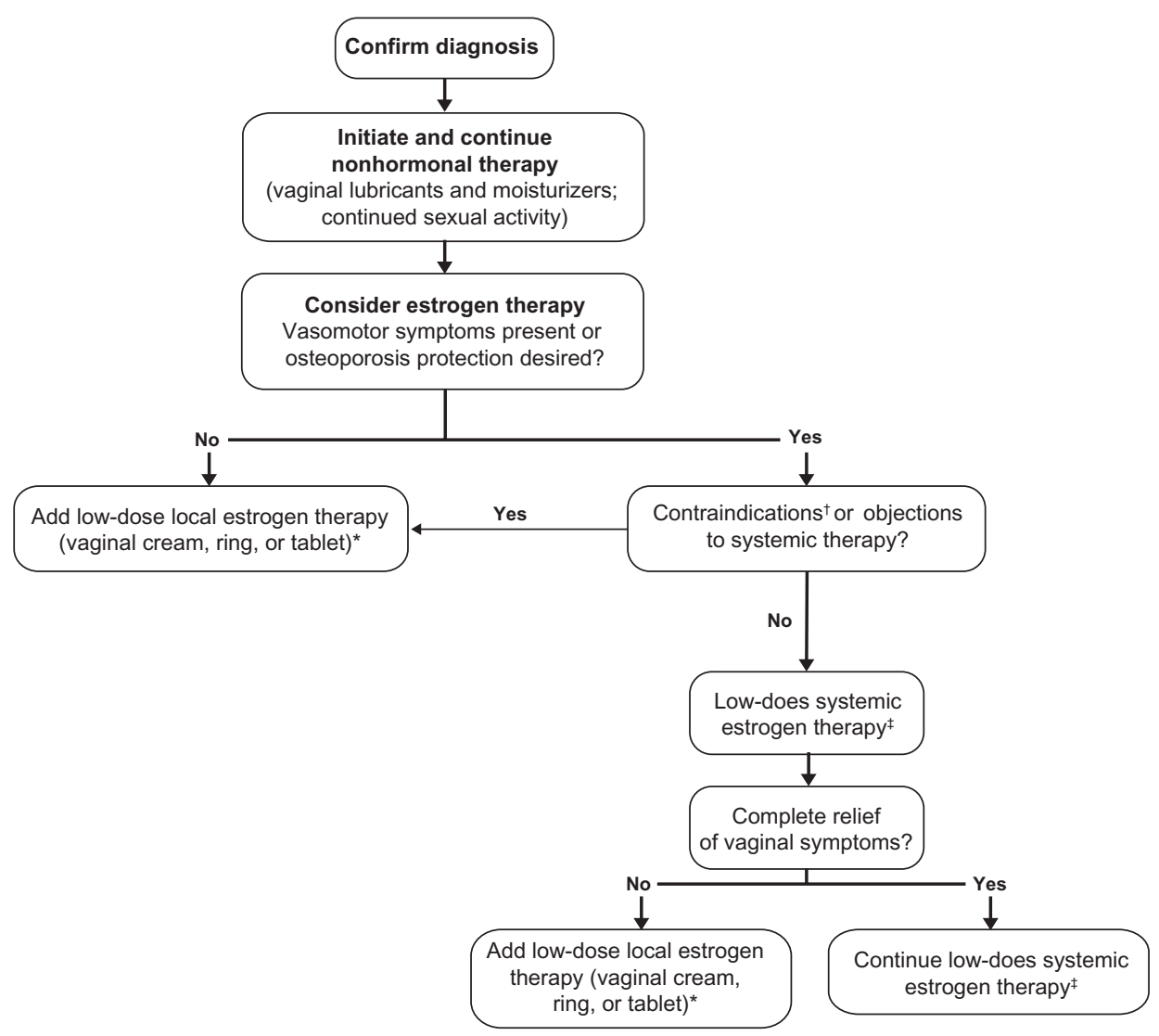

Figure I Approach to treatment of vaginal atrophy.,11

Notes: *Use in patients with hormone-dependent cancer has not been well studied; risk/benefit should be determined on a case-by-case basis. ${ }^{9}$

tUndiagnosed abnormal uterine bleeding, breast cancer (except in appropriately selected patients being treated for metastatic disease), estrogen-dependent neoplasia, deep vein thrombosis or pulmonary embolism, arterial thromboembolic disease within the past year, liver disease/dysfunction, pregnancy, or hypersensitivity to estrogen therapy. ${ }^{35}$ ${ }^{\ddagger}$ Concomitant progestogen therapy is recommended in women with an intact uterus and who are receiving systemic estrogen therapy to prevent endometrial proliferation and adenocarcinoma. ${ }^{12}$

to systemic estrogen therapy, systemic estrogen therapy may be considered as a treatment for vaginal atrophy. ${ }^{12}$ These patients should be informed of the potential risks of therapy, including deep vein thrombosis, pulmonary embolism, coronary heart disease, and breast cancer. Low doses of orally administered conjugated equine estrogens $(0.3 \mathrm{mg} /$ day $)$, ultra-low doses of continuous combined hormone-replacement therapy (estradiol $0.5 \mathrm{mg}$ /day plus norethisterone acetate 0.1 to $0.25 \mathrm{mg}$ /day), and ultra-low-dose transdermal estradiol ( 0.0125 to $0.014 \mathrm{mg} /$ day) have shown safety and beneficial effects on both vasomotor symptoms and measures of vaginal atrophy (eg, $\mathrm{pH}$, maturation index, vaginal symptoms) in studies of up to 2 years' duration. ${ }^{13-19}$ However, oral estradiol is less commonly prescribed because it undergoes significant first-pass metabolism through the liver, which leads to a large reduction in bioavailable drug. ${ }^{20}$ Generally, for women with an intact uterus, concomitant progestogen therapy is recommended when receiving systemic estrogen therapy, to prevent endometrial hyperplasia and adenocarcinoma. ${ }^{12}$
In women with a history of hormone-dependent cancer, the potential risks associated with systemic estrogen therapy with or without progestogen may outweigh potential benefits; therefore, systemic therapy is best avoided in this subgroup of patients with vaginal atrophy. Also, not all women experience complete relief of vaginal symptoms with systemic estrogen therapy and additional local estrogen therapy may be required for persistent vaginal symptoms. ${ }^{12}$

Local estrogen therapy is commonly recommended for patients with primarily vaginal symptoms and moderate-tosevere vaginal atrophy. Commercially available local estrogen therapies (Table 2) include an estradiol vaginal cream, ${ }^{21}$ a conjugated estrogen (CE) vaginal cream, ${ }^{22}$ an estradiol vaginal ring, ${ }^{23}$ and an estradiol vaginal tablet. ${ }^{24}$ These various formulations have shown comparable effectiveness ${ }^{25,26}$ for the relief of vaginal atrophy symptoms, including vaginal dryness, itching, discomfort, and dyspareunia; thus, therapy selection for individual patients is largely driven by provider and patient preference. ${ }^{9}$ The potential benefits and limitations of the available formulations are summarized in Table 2 . 
Table 2 Commercially available local estrogen therapies

\begin{tabular}{|c|c|c|c|c|}
\hline Formulation & Product & Benefits & Limitations & Dosing \\
\hline Vaginal cream & $\begin{array}{l}\text { Estrace }^{\circledR} \text { (estradiol, } 100 \text { mcg/g; } \\
\text { Warner Chilcott, Rockaway, NJ) } \\
\text { Premarin }{ }^{\circledR}(\text { conjugated estrogens, } \\
625 \text { mcg/g; Pfizer, New York, NY) }{ }^{22}\end{array}$ & $\begin{array}{l}\text { Dosing flexibility; } \\
\text { inexpensive }\end{array}$ & $\begin{array}{l}\text { Poor dose control/ } \\
\text { potential for overdosing; } \\
\text { complex regimen } \\
\text { (adherence); potential } \\
\text { for leakage }\end{array}$ & $\begin{array}{l}\text { Estrace: } 2-4 \mathrm{~g} / \text { day } \times \text { I or } 2 \text { weeks, } \\
\text { gradually reduced to half initial } \\
\text { dose } \times \text { I or } 2 \text { weeks; I g I-3 times } \\
\text { weekly for maintenance } \\
\text { Premarin: } 0.5-2 \text { g/day for } 2 \text { I days; off } \\
\text { for } 7 \text { days; repeat or } 0.5 \mathrm{~g} \text { twice weekly }\end{array}$ \\
\hline Vaginal ring & 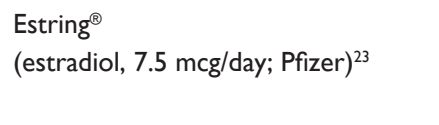 & $\begin{array}{l}\text { Fixed-dose/minimal } \\
\text { risk for overdose; } \\
\text { infrequent dosing }\end{array}$ & $\begin{array}{l}\text { May fall out; may be } \\
\text { difficult to insert/remove; } \\
\text { may affect sexual intercourse }\end{array}$ & Replace ring every 3 months \\
\hline Vaginal tablet & $\begin{array}{l}\text { Vagifem }^{\circledast} \text { (estradiol, } 10 \text { mcg*; Novo } \\
\text { Nordisk A/S, Bagsvaerd, Denmark) }{ }^{24}\end{array}$ & $\begin{array}{l}\text { Fixed-dose/minimal } \\
\text { risk for overdose }\end{array}$ & Adherence to regimen & $\begin{array}{l}\text { Vagifem: I tablet daily } \times 2 \text { weeks; } \\
\text { twice weekly thereafter }\end{array}$ \\
\hline
\end{tabular}

Note: *The $25 \mathrm{mcg}$ vaginal tablet, discontinued July 2010, was replaced with the $10 \mathrm{mcg}$ tablet.

Local estrogen therapy can provide sufficient estrogen to the vaginal tissues, with limited systemic absorption, ${ }^{9}$ so lowdose vaginal estrogen may achieve an effect in the tissue that is similar to the response obtained from oral or transdermal dosing regimens.

\section{Safety profile of low-dose local vaginal estrogen}

Several large studies have provided evidence for the endometrial safety of various low-dose local vaginal estrogen formulations. ${ }^{27-29}$ The lowest commercially available formulation, the $10 \mathrm{mcg}$ estradiol biweekly vaginal tablet, was associated with no increased risk for endometrial hyperplasia or carcinoma in postmenopausal women treated for 52 weeks ( $0.52 \%$ incidence of endometrial hyperplasia or carcinoma in 386 evaluable biopsy samples, compared with $0 \%$ to $1 \%$ background incidence). ${ }^{27}$ In another study, the vaginal ring, which releases $7.5 \mathrm{mcg}$ estradiol per day, was associated with endometrial thickening to $>7 \mathrm{~mm}$ in two of 126 women at 48 weeks, but evidence of proliferation was absent at biopsy. ${ }^{28}$ Additionally, low-dose regimens of the CE cream $(0.3 \mathrm{mg}$ CE once daily [21 days on/7 days off] or twice weekly) did not result in endometrial hyperplasia or carcinoma in 155 biopsies evaluated at 52 weeks. ${ }^{29}$ The studies mentioned and others ${ }^{25}$ show that it is probable that low-dose local vaginal estrogen poses a minimal risk for endometrial hyperplasia and carcinoma. Therefore, NAMS advises that progestogen therapy is generally not needed when low-dose estrogen is administered locally for the treatment of vaginal atrophy. ${ }^{12}$

Women living with breast cancer and breast cancer survivors comprise a population of particular interest with regard to the safety of vaginal estrogen preparations. Their numbers are growing because the overall incidence of breast cancer is increasing, while improved cancer treatments are improving survival times. ${ }^{30}$ The risks associated with vaginal estrogen use in women with a history of breast cancer have been addressed in the literature. Pruthi et $\mathrm{a}^{31}$ concluded that safety and risk of recurrence is undefined in this population; however, the $10 \mathrm{mcg}$ estradiol vaginal tablet or estradiol vaginal ring can be considered after appropriate disclosure to the patient. Dew et $\mathrm{al}^{32}$ evaluated the risk for breast cancer recurrence with the use of low-dose vaginal estrogen and were unable to show an increased risk. However, a small study in which six women were using aromatase inhibitors and vaginal estrogen $(25 \mathrm{mcg}$ estradiol vaginal tablet, which has since been replaced with a $10 \mathrm{mcg}$ estradiol vaginal tablet) showed a short-term increase in serum estradiol that varied by individual. ${ }^{33}$ In two of the six women, serum estradiol levels did not return to baseline. Based on these results, Kendall et a ${ }^{33}$ cautioned against using vaginal estrogen in patients using aromatase inhibitors because systemic absorption of the former could increase serum estradiol, thereby negating the effectiveness of the latter, which work by near-total suppression of estrogenic stimulation. ${ }^{33}$

Health care providers (HCPs) should counsel women who have a history of breast cancer regarding the risks and benefits of local vaginal estrogen for the treatment of vaginal atrophy. Quality of life issues, including sexual health, should also be addressed to help women make an informed decision regarding this therapy. Clinicians should also be aware that using local vaginal estrogen for women who have a history of breast cancer is considered off-label because of the black-box warning included in the package insert, which describes the increased risk for breast cancer associated with estrogen plus progestin therapy found in the Women's Health Initiative study. ${ }^{24}$ 


\section{Overcoming barriers to the use of local estrogen therapy}

Multiple barriers prevent the treatment of vaginal atrophy with local estrogen therapy in women who may benefit from treatment (Table 3). First, many women are uncomfortable discussing their vaginal health. Results of one international survey indicated that the majority of women with vaginal discomfort $(\geq 70 \%)$ had not discussed it with their general practitioner or gynecologist. ${ }^{2} \mathrm{HCPs}$ can address vaginal atrophy by initiating a discussion about vaginal health during preventive health evaluations. This discussion can be individually adapted to each patient's learning preferences and should reinforce that vaginal atrophy is common among peri- and postmenopausal women. In addition, it should include an open conversation regarding improvement or exacerbation of symptoms with over-the-counter products. If a patient reports vaginal discomfort, with or without selftreatment, a physical examination should be performed. If evidence of vaginal atrophy is noted, a discussion about current treatment recommendations should follow.

Some women may be hesitant to use estrogen therapy, even if they have significant symptoms. Early termination of the Women's Health Initiative randomized controlled trial ${ }^{34}$ and subsequent media coverage raised public awareness of the potential risks of standard-dose systemic hormone therapy. Adverse effects, such as uterine bleeding, breast tenderness, nausea, abdominal bloating, and fluid retention, ${ }^{35}$ may further hinder patient acceptance of systemic estrogen or estrogen plus progestogen therapy. Education regarding the risks and benefits of estrogen therapy, including the improved riskbenefit profiles of less-than-standard-dose systemic therapies ${ }^{36}$

Table 3 Potential solutions to common barriers to identification and treatment of vaginal atrophy

\begin{tabular}{|c|c|}
\hline Barrier & Potential solution \\
\hline $\begin{array}{l}\text { Patient uncomfortable } \\
\text { discussing vaginal } \\
\text { atrophy }\end{array}$ & $\begin{array}{l}\text { Initiation of regular discussions of vaginal } \\
\text { health during preventive health evaluations; } \\
\text { assure patient that vaginal atrophy is common } \\
\text { and treatable; use the } 5 \mathrm{~A}^{\text {'s }} \text { * of behavioral } \\
\text { counseling }{ }^{41} \text { to guide discussion }\end{array}$ \\
\hline $\begin{array}{l}\text { Patient hesitant to } \\
\text { use estrogen } \\
\text { therapy }\end{array}$ & $\begin{array}{l}\text { Education about benefits and risks; highlight } \\
\text { differences between standard-dose therapies, } \\
\text { systemic therapies, and low-dose local } \\
\text { therapies }\end{array}$ \\
\hline $\begin{array}{l}\text { Resistance to use } \\
\text { of local therapies }\end{array}$ & $\begin{array}{l}\text { Individualization of therapy with which the } \\
\text { patient is most comfortable; set expectations } \\
\text { regarding use/effects; arrange appropriate } \\
\text { monitoring/follow-up }\end{array}$ \\
\hline
\end{tabular}

Note: *Assess, Advise, Agree, Assist, Arrange. and the endometrial safety of low-dose local therapies, ${ }^{27-29} \mathrm{can}$ help facilitate acceptance among women for whom estrogen therapy is appropriate. It may be helpful to mention to a patient that the amount of estradiol administered locally (eg, by vaginal tablet or vaginal ring) in a low dose is much less than that administered in a standard oral dose. While a standard oral dose of estradiol is considered $1 \mathrm{mg} /$ day, the vaginal tablet regimen (one $10 \mathrm{mcg}$ tablet daily for 2 weeks followed by one tablet twice weekly thereafter ${ }^{24}$ ) exposes a patient to about $1.14 \mathrm{mg}$ estradiol (ie, roughly the same amount as the standard oral dose) over an entire year of treatment. For further comparison, patients using the ring are exposed to about $2.74 \mathrm{mg}$ estradiol per year, while patients using the creams are generally exposed to more estrogen, depending on the regimen. Closely following these total doses, systemic absorption of estrogen remains lowest with the vaginal tablet, ${ }^{37}$ followed by the ring ${ }^{38}$ and creams. ${ }^{39,40}$

Barriers related to the use of local vaginal estrogen in particular might include its lack of effect on bone loss and vasomotor symptoms, the need for vaginal insertion, irregular treatment intervals, and concerns regarding the potential for improper dosing. Patients may also be apprehensive about potential discomforts associated with use of a vaginal medication (eg, leakage with creams). Additionally, patients may be uncertain regarding the uterine safety of local vaginal estrogen; therefore, HCPs should counsel women effectively regarding the safety data of various formulations. Counseling should also include advising women that use of the lowest effective dose of local vaginal estrogen is recommended to minimize systemic absorption and associated risks. ${ }^{9}$

\section{Counseling intervention}

The decision for a woman to use a hormone medication depends on many individualized factors. A patient's biological and psychological response to midlife and aging, tolerance for symptoms and side effects of the medication, and risk/benefit profile will influence both the HCP's recommendation for intervention and the woman's decision to implement the intervention. The Counseling and Behavioral Interventions Work Group of the United States Preventive Services Task Force recommends the "5 A's" construct as a clinical counseling strategy ${ }^{41}$ :

- Assess

- Advise

- Agree

- Assist

- Arrange 
Counseling using the 5 A's may be useful for overcoming the communication barriers between patients and their HCPs. Routine assessment of vaginal health during preventive health evaluations should facilitate timely identification of vaginal atrophy. HCPs can then provide personalized advice regarding vaginal atrophy and help the patient understand the goals, benefits, and risks of treatment and agree to undergo treatment. Additional counseling about proper treatment administration and what to expect from therapy assists the patient in achieving her goals, while arranging appropriate follow-up appointments should facilitate long-term management of this chronic condition.

\section{Conclusion}

HCPs such as gynecologists, primary care physicians, nurses, and nurse practitioners can play an essential role in reducing the barriers associated with discussion and treatment of vaginal atrophy. A discussion of the pathophysiology of vaginal atrophy, treatment options (including risks and benefits of treatment), and overall sexual health is pertinent to preventive health care. Additionally, a brief review of the safety profile of local vaginal estrogen may help women make informed decisions regarding their treatment. Counseling intervention using the $5 \mathrm{~A}$ 's can empower women to manage their vaginal symptoms effectively in the long-term, potentially improving patient quality of life.

\section{Acknowledgments}

Editorial assistance was provided by Tamara Rahim Grow, PhD, ETHOS Health Communications, Newtown, Pennsylvania, with financial assistance from Novo Nordisk, Inc, Princeton, New Jersey, in compliance with international guidelines on good publication practice.

\section{Disclosure}

LAC participated in an advisory board in October 2011 for Novo Nordisk; this program was completely independent of this article. She received no remuneration of any kind for the development of this article and declares no other conflicts of interest in this work.

\section{References}

1. Santoro N, Komi J. Prevalence and impact of vaginal symptoms among postmenopausal women. J Sex Med. 2009;6(8):2133-2142.

2. Nappi RE, Kokot-Kierepa M. Women's voices in the menopause: results from an international survey on vaginal atrophy. Maturitas. 2010; 67(3):233-238.

3. Crandall C, Petersen L, Ganz PA, Greendale GA. Association of breast cancer and its therapy with menopause-related symptoms. Menopause. 2004;11(5):519-530.
4. Sturdee DW, Panay N; International Menopause Society Writing Group. Recommendations for the management of postmenopausal vaginal atrophy. Climacteric. 2010;13(6):509-522.

5. Levine KB, Williams RE, Hartmann KE. Vulvovaginal atrophy is strongly associated with female sexual dysfunction among sexually active postmenopausal women. Menopause. 2008;15(4 Pt 1): 661-666.

6. Krychman M. Impact of vaginal atrophy on quality of life and sexuality. OBG Manage. 2010;22(11):S14-S19.

7. Kingsberg S, Kellogg S, Krychman M. Treating dyspareunia caused by vaginal atrophy: a review of treatment options using vaginal estrogen therapy. Int J Womens Health. 2010;1:105-111.

8. Reimer A, Johnson L. Atrophic vaginitis: signs, symptoms, and better outcomes. Nurse Pract. 2011;36(1):22-28.

9. Deniz G, Antoine C, Liebens F, Carly B, Pastijn A, Rozenberg S. Treatment of premature menopause in breast cancer patients. Acta Chir Belg. 2007;107(3):263-266.

10. Lara LA, Useche B, Ferriani RA, et al. The effects of hypoestrogenism on the vaginal wall: interference with the normal sexual response. $J$ Sex Med. 2009;6(1):30-39.

11. Mac Bride MB, Rhodes DJ, Shuster LT. Vulvovaginal atrophy. Mayo Clin Proc. 2010;85(1):87-94.

12. North American Menopause Society The 2012 hormone therapy position statement of: The North American Menopause Society. Menopause. 2012;19(3):257-271.

13. Utian WH, Shoupe D, Bachmann G, Pinkerton JV, Pickar JH. Relief of vasomotor symptoms and vaginal atrophy with lower doses of conjugated equine estrogens and medroxyprogesterone acetate. Fertil Steril. 2001;75(6):1065-1079.

14. Bachmann GA, Schaefers M, Uddin A, Utian WH. Lowest effective transdermal 17beta-estradiol dose for relief of hot flushes in postmenopausal women: a randomized controlled trial. Obstet Gynecol. 2007;110(4):771-779.

15. Bachmann GA, Schaefers M, Uddin A, Utian WH. Microdose transdermal estrogen therapy for relief of vulvovaginal symptoms in postmenopausal women. Menopause. 2009;16(5): 877-882.

16. Gupta P, Ozel B, Stanczyk FZ, Felix JC, Mishell DR Jr. The effect of transdermal and vaginal estrogen therapy on markers of postmenopausal estrogen status. Menopause. 2008;15(1):94-97.

17. Simon JA, Bouchard C, Waldbaum A, Utian W, Zborowski J, Snabes MC. Low dose of transdermal estradiol gel for treatment of symptomatic postmenopausal women: a randomized controlled trial. Obstet Gynecol. 2007;109(3):588-596.

18. Johnson SR, Ettinger B, Macer JL, Ensrud KE, Quan J, Grady D. Uterine and vaginal effects of unopposed ultralow-dose transdermal estradiol. Obstet Gynecol. 2005;105(4):779-787.

19. Panay N, Ylikorkala O, Archer DF, Gut R, Lang E. Ultra-low-dose estradiol and norethisterone acetate: effective menopausal symptom relief. Climacteric. 2007;10(2):120-131.

20. Boothby LA, Doering PL, Kipersztok S. Bioidentical hormone therapy: a review. Menopause. 2004;11(3):356-367.

21. Bachmann G, Santen RJ. Clinical manifestations and diagnosis of vaginal atrophy. In: Basow DS, editor. UpToDate. Waltham, MA: UpToDate; 2011. Available from: http://www.uptodate.com/contents/clinicalmanifestations-and-diagnosis-of-vaginal-atrophy?source=search_res ult\&search=Clinical+manifestations+and+diagnosis+of+vaginal+atro phy\&selectedTitle=1 45. Accessed August 28, 2012.

22. Bond S, Horton LS. Management of postmenopausal vaginal symptoms in women. J Gerontol Nurs. 2010;36(7):3-7.

23. Roy S, Caillouette JC, Roy T, Faden JS. Vaginal pH is similar to follicle-stimulating hormone for menopause diagnosis. Am J Obstet Gynecol. 2004;190(5):1272-1277.

24. Brunner RL, Aragaki A, Barnabei V, et al. Menopausal symptom experience before and after stopping estrogen therapy in the Women's Health Initiative randomized, placebo-controlled trial. Menopause. 2010; 17(5):946-954. 
25. Suckling J, Lethaby A, Kennedy R. Local oestrogen for vaginal atrophy in postmenopausal women. Cochrane Database Syst Rev. 2006;4:CD001500.

26. Simon J, Nachtigall L, Gut R, Lang E, Archer DF, Utian W. Effective treatment of vaginal atrophy with an ultra-low-dose estradiol vaginal tablet. Obstet Gynecol. 2008;112(5):1053-1060.

27. Simon J, Nachtigall L, Ulrich LG, Eugster-Hausmann M, Gut R. Endometrial safety of ultra-low-dose estradiol vaginal tablets. Obstet Gynecol. 2010;116(4):876-883.

28. Weisberg E, Ayton R, Darling G, et al. Endometrial and vaginal effects of low-dose estradiol delivered by vaginal ring or vaginal tablet. Climacteric. 2005;8(1):83-92.

29. Bachmann G, Bouchard C, Hoppe D, et al. Efficacy and safety of lowdose regimens of conjugated estrogens cream administered vaginally. Menopause. 2009;16(4):719-727.

30. Ponzone R, Biglia N, Jacomuzzi ME, Maggiorotto F, Mariani L, Sismondi P. Vaginal oestrogen therapy after breast cancer: is it safe? Eur J Cancer. 2005;41(17):2673-2681.

31. Pruthi S, Simon JA, Early AP. Current overview of the management of urogenital atrophy in women with breast cancer. Breast J. 2011;17(4): 403-408.

32. Dew JE, Wren BG, Eden JA. A cohort study of topical vaginal estrogen therapy in women previously treated for breast cancer. Climacteric. 2003;6(1):45-52.

33. Kendall A, Dowsett M, Folkerd E, Smith I. Caution: Vaginal estradiol appears to be contraindicated in postmenopausal women on adjuvant aromatase inhibitors. Ann Oncol. 2006;17(4):584-587.
34. Rossouw JE, Anderson GL, Prentice RL, et al; Writing Group for the Women's Health Initiative Investigators. Risks and benefits of estrogen plus progestin in healthy postmenopausal women: principal results From the Women's Health Initiative randomized controlled trial. JAMA. 2002;288(3):321-333.

35. North American Menopause Society. Menopause Practice: A Clinician's Guide. 4th ed. Mayfield Heights, OH: The North American Menopause Society; 2010

36. Langer RD. Efficacy, safety, and tolerability of low-dose hormone therapy in managing menopausal symptoms. J Am Board Fam Med. 2009;22(5):563-573.

37. Eugster-Hausmann M, Waitzinger J, Lehnick D. Minimized estradiol absorption with ultra-low-dose 10 microg 17 beta-estradiol vaginal tablets. Climacteric. 2010;13(3):219-227.

38. Bachmann $\mathrm{G}$. The estradiol vaginal ring - a study of existing clinical data. Maturitas. 1995;22 Suppl:S21-S29.

39. Martin PL, Yen SS, Burnier AM, Hermann H. Systemic absorption and sustained effects of vaginal estrogen creams. JAMA. 1979;242(24) 2699-2700.

40. Labrie F, Cusan L, Gomez JL, et al. Effect of one-week treatment with vaginal estrogen preparations on serum estrogen levels in postmenopausal women. Menopause. 2009;16(1):30-36.

41. Whitlock EP, Orleans CT, Pender N, Allan J. Evaluating primary care behavioral counseling interventions: an evidence-based approach. Am J Prev Med. 2002;22(4):267-284.
International Journal of Women's Health

\section{Publish your work in this journal}

The International Journal of Women's Health is an international, peerreviewed open-access journal publishing original research, reports, reviews and commentaries on all aspects of women's healthcare including gynecology, obstetrics, and breast cancer. Subject areas include Chronic conditions (migraine headaches, arthritis, osteoporosis);

\section{Dovepress}

Endocrine and autoimmune syndromes; Sexual and reproductive health; Psychological and psychosocial conditions. The manuscript management system is completely online and includes a very quick and fair peer-review system. Visit http://www.dovepress.com/ testimonials.php to read real quotes from published authors. 